\title{
Electrophysiological abnormalities in the transplanted human heart
}

\author{
RODNEY S BEXTON, ANTHONY W NATHAN,^ KEVIN J HELLESTRAND, RICHARD \\ CORY-PEARCE, $\uparrow$ ROWORTH A J SPURRELL, TERENCE A H ENGLISH, A JOHN CAMM‡
}

From the Department of Cardiology, St Bartholomew's Hospital, London, and the British Heart Foundation Heart Transplant Research Unit, Papworth Hospital, Papworth Everard, Cambridge

SUMMARY Fourteen relatively long term survivors of cardiac transplantation underwent systematic electrophysiological evaluation and ambulatory electrocardiographic monitoring. Six patients had prolonged conduction intervals during sinus rhythm. Sinus node function could be assessed in all donor atria and in 10 recipient atria. Sinus node recovery times were prolonged in four of the donor atria and in six recipient atria. In the donor atria abnormalities of sinus node automaticity were invariably associated with abnormalities of sinoatrial conduction. Four patients showed functional duality of atrioventricular nodal conduction during programmed extrastimulation, but no patient developed re-entrant arrhythmia. During ambulatory electrocardiographic monitoring no pronounced tachyarrhythmias were recorded. Three patients showed abnormalities of sinus node impulse formation. All three patients had abnormal sinus node recovery times during their electrophysiological study. Long term survivors of cardiac transplantation have a high incidence of electrophysiological abnormalities. Abnormalities of donor sinus node function are probably of clinical significance. The clinical significance of abnormalities detected within the atrioventricular conduction system of the denervated heart remains to be elucidated.

The therapeutic and prognostic implications of abnormalities found during invasive electrophysiological testing have been widely reported. ${ }^{1-5}$ Although the sensitivity and specificity of formal testing of sinus node function in man may be limited, ${ }^{67}$ abnormalities within the atrioventricular conduction system, particularly in certain subgroups of patients or when associated with other cardiovascular abnormalities, appear to carry greater therapeutic implications..$^{8-10}$ The significance of electrophysiological abnormalities in asymptomatic, apparently normal subjects has obviously not been determined.

Although previous reports from both Stanford University, California, and Papworth Hospital, Cambridge, have indicated a high incidence of both atrial and ventricular arrhythmias in transplant patients ${ }^{1112}$ together with a relatively high incidence of sinus node

\footnotetext{
^Recipient of British Heart Foundation fellowship.

†British Heart Foundation senior research fellow.

$\ddagger$ Wellcome senior lecturer.
}

Accepted for publication 19 July 1983 disease, 1314 the incidence of abnormalities found during electrophysiological testing has not been reported. The purpose of this investigation was to detail the abnormalities detected during a systematic electrophysiological evaluation and during the ambulatory electrocardiographic monitoring of a group of relatively long term survivors of cardiac transplantation.

\section{Patients and methods}

Fourteen cardiac transplant recipients underwent routine electrophysiological evaluation four to 28 (mean 14) months after transplantation. Their ages ranged from 24 to 54 (mean 38) years, and 13 patients were men (Table). The study was performed because of the previous reports of a high incidence of sinus node and conduction system disease in patients after cardiac transplantation, ${ }^{11-13}$ which in at least one study has been associated with an increased mortality. ${ }^{14}$ All patients were completely asymptomatic with no haematological, biochemical, or electrocardiographic evidence of rejection. All patients were 
Table Patient details and results

\begin{tabular}{|c|c|c|c|c|c|c|c|}
\hline Case No. & Sex & $\begin{array}{l}\text { Diagnosis } \\
\text { before transplant }\end{array}$ & $\begin{array}{l}\text { Age at time of } \\
\text { study (years) }\end{array}$ & $\begin{array}{l}\text { Survival at time } \\
\text { of study (months) }\end{array}$ & $\begin{array}{l}\text { Abnormal } \\
\text { conduction } \\
\text { intervals }\end{array}$ & $\begin{array}{l}\text { Abnormal } \\
\text { sinus node } \\
\text { function tests }\end{array}$ & $\begin{array}{l}\text { Abnormal } \\
\text { refractory } \\
\text { period }\end{array}$ \\
\hline $\begin{array}{r}1 \\
2 \\
3 \\
4 \\
5 \\
6 \\
7 \\
8 \\
9 \\
10 \\
11 \\
12 \\
13 \\
14\end{array}$ & $\begin{array}{l}M \\
M \\
M \\
M \\
M \\
M \\
M \\
M \\
F \\
M \\
M \\
M \\
M \\
M\end{array}$ & $\begin{array}{l}\text { IHD } \\
\text { CM } \\
\text { IHD } \\
C M \\
C M \\
C M \\
\text { IHD } \\
\text { IHD } \\
\text { CM } \\
\text { IHD } \\
\text { IHD } \\
\text { IHD } \\
\text { IHD } \\
\text { IHD }\end{array}$ & $\begin{array}{l}43 \\
41 \\
44 \\
37 \\
24 \\
24 \\
31 \\
54 \\
34 \\
28 \\
49 \\
35 \\
53 \\
42\end{array}$ & $\begin{array}{r}4 \\
9 \\
11 \\
18 \\
17 \\
14 \\
22 \\
28 \\
8 \\
14 \\
18 \\
17 \\
15 \\
7\end{array}$ & $\begin{array}{l}+ \\
- \\
+ \\
- \\
- \\
+ \\
+ \\
+ \\
- \\
- \\
- \\
- \\
+ \\
-\end{array}$ & $\begin{array}{l}- \\
- \\
- \\
- \\
- \\
- \\
+ \\
+ \\
+ \\
+ \\
- \\
- \\
- \\
+\end{array}$ & $\begin{array}{l}- \\
-\star \\
- \\
- \\
- \\
-\star \\
-^{\star} \\
-\star \\
- \\
- \\
- \\
- \\
- \\
-\end{array}$ \\
\hline
\end{tabular}

IHD, ischaemic heart disease; CM, cardiomyopathy; *, functional duality of atrioventricular nodal conduction; + , present; - , absent.

taking prednisolone and azathioprine as routine immunosuppressive treatment, and no patient was taking cardioactive drugs. Seven patients had implanted epicardial ventricular demand pacemakers, which had been implanted at operation because of the previously reported poor prognosis associated with early sinus node dysfunction after transplantation. ${ }^{14}$

\section{ELECTROPHYSIOLOGICAL STUDY}

The patients were studied in the non-sedated, postabsorptive state after written informed consent had been given. Prior approval for the study had been obtained from the ethical committee of St Bartholomew's Hospital. All patients were premedicated with intramuscular flucloxacillin, which was continued orally for two days after the electrophysiological study, and there was no appreciable short term or long term morbidity associated with the study. Five pacing electrodes were inserted into the right femoral vein under local anaesthesia and positioned within the heart using fluoroscopic guidance. During orthotopic cardiac transplantation ${ }^{15}$ the posterior portions of the recipient atria are left in situ together with the recipient sinus node. A quadripolar electrode was therefore positioned at the junction between the superior vena cava and right atrium to record and stimulate the recipient atrial remnants. Two bipolar electrodes were positioned within the appendage of the donor right atrium for recording and stimulation. An electrode was manipulated across the septal leaflet of the tricuspid valve to record distinct electrograms from the low right atrium, His potential, and the proximal portion of the right ventricular septum. A further electrode was advanced to the apex of the right ventricle for stimulation.

Bipolar endocardial signals from the electrodes were passed through appropriate amplification and filtering and recorded on a Mingograf ink jet recorder at $100 \mathrm{~mm} / \mathrm{s}$, together with four surface electrocardiographic leads. Intracardiac stimulation was achieved using constant voltage, current limited square wave pulses of $1.5-2.5 \mathrm{~ms}$ duration at about twice diastolic threshold.

Conduction intervals were measured during sinus rhythm and during constant rate donor right atrial pacing at cycle lengths of $500 \mathrm{~ms}$ and $400 \mathrm{~ms}$. The intervals were measured according to previously described definitions ${ }^{16}$ and defined as normal or abnormal based on the normal range of values for normally innervated adult man. ${ }^{17-20}$ Sinus node recovery time was assessed by overdrive suppression ${ }^{21}$ and was defined as the maximum sinus pause after stopping right atrial pacing at rates of 110 (if appropriate), 130,150 , and 170 beats/min for periods of 15 , 30 , and $60 \mathrm{~s}$ at each rate. The results were corrected by subtracting sinus cycle length. ${ }^{22}$ The upper limit of normal for sinus node recovery time was accepted as $1400 \mathrm{~ms}^{23}$ and for corrected recovery time as 525 ms. ${ }^{22}$ Both donor and recipient sinus node recovery times were assessed during synchronous pacing of both sets of atria. Sinoatrial conduction time was assessed by introducing programmed atrial beats during sinus rhythm and calculated according to the revised method of Strauss et al. ${ }^{24}$ The upper limit of normal was accepted as $206 \mathrm{~ms}^{25}$ Both donor and recipient sinoatrial conduction times were assessed.

Anterograde and retrograde conduction characteristics and refractoriness of the donor heart were determined by introducing an extrastimulus after regular donor atrial or ventricular pacing ${ }^{26} 27$ at cycle lengths of $500 \mathrm{~ms}$ and $400 \mathrm{~ms}$. Standard definitions ${ }^{162627}$ and normal values ${ }^{27-29}$ were used for estimating the effective and functional refractory periods of the various components of the atrioventricular conduction system.

Functional duality of atrioventricular nodal con- 
duction was considered to be present when, during assessment of atrioventricular nodal refractoriness, there was a discontinuity on the anterograde conduction curve with a sudden jump in the H1-H2 interval, and therefore concomitantly in the A2- $\mathrm{H} 2$ interval, at a critical A1-A2 coupling interval. ${ }^{30-32}$ Duality of atrioventricular nodal conduction was defined as a jump in the $\mathrm{H} 1-\mathrm{H} 2$ interval of $40 \mathrm{~ms}$ or greater for a decrease of $10 \mathrm{~ms}$ in the A1-A2 coupling interval. ${ }^{32}$ The curve to the right of the discontinuity represents fast atrioventricular nodal pathway conduction and to the left slow pathway conduction.

In one patient the electrophysiological study had to be ended prematurely for technical reasons. Conduction intervals and sinus node function tests from 14 patients and refractory periods from 13 patients are therefore reported below.

\section{AMBULATORY ELECTROCARDIOGRAPHIC MONITORING}

Each patient underwent 24 hour ambulatory electrocardiographic monitoring using either four inch reel to reel two channel tape recorders or two channel cassette recorders. The recordings were subjected to automatic and technician analysis to assess the incidence of arrhythmic episodes of any origin or aetiology or evidence of sinus node or conduction system disease.

\section{Results}

\section{CONDUCTION INTERVALS}

During sinus rhythm four patients had prolonged PA intervals $(55 \mathrm{~ms}, 60 \mathrm{~ms}, 60 \mathrm{~ms}$, and $70 \mathrm{~ms}$ ), two patients had prolonged HV intervals (both $60 \mathrm{~ms}$ ), and two patients had prolonged QRS durations (115 $\mathrm{ms}$ and $130 \mathrm{~ms}$ ) (Fig. 1). Both the patients with prolonged QRS durations had complete right bundle branch block. In one of these patients the abnormality

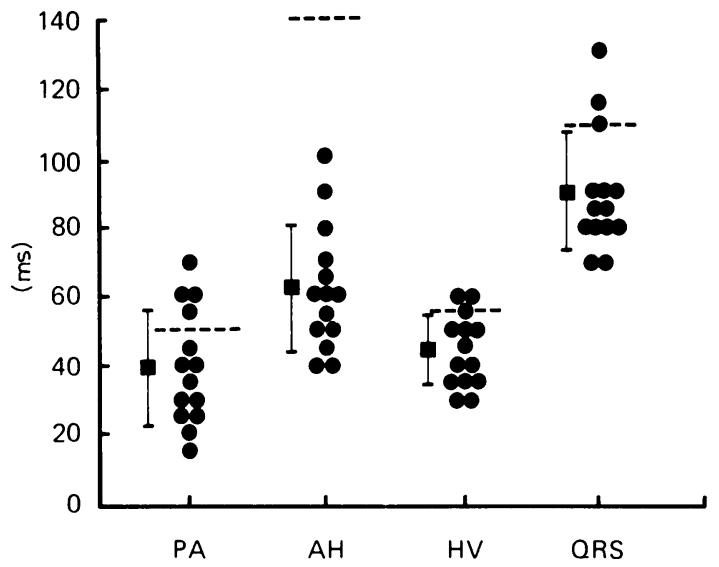

Fig. 1 Conduction intervals in individual patients. The mean $\pm I S D$ is also indicated. Dashed lines indicate the upper limit of normal for normally innervated man.

had been present on the donor electrocardiogram before transplantation. Although eight patients had a prolonged QTc, no patient had a prolonged QT interval measured during sinus rhythm based on normal values. $^{20}$

\section{SINUS NODE FUNCTION (Fig. 2)}

In two patients no electrical activity of the recipient atrium was recorded nor could this atrium be paced despite high pacing energies. In one patient the recipient atrium was fibrillating while the donor atrium remained in sinus rhythm (Fig. 3). In one patient the donor and recipient atria remained synchronised throughout a variety of physiological and pacing manoeuvres. This unique situation has been reported elsewhere. ${ }^{33}$ The sinus node function of 14 donor atria and 10 recipient atria could therefore be assessed.
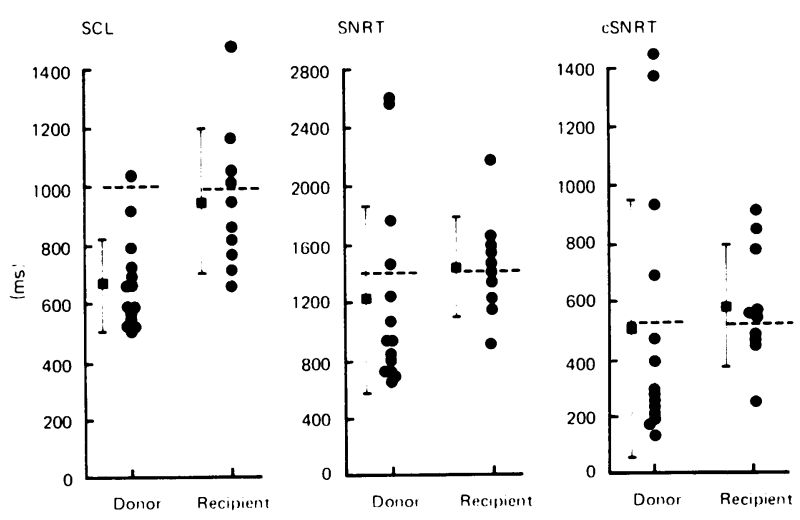

Fig. 2 Results of sinus node function tests in individual patients. The mean $\pm 1 S D$ is also indicated. Dashed lines indicate the upper limit of normal for normally innervated man. $S C L$, sinus cycle length; SNRT, sinus node recovery time; cSNRT, corrected sinus node recovery time. 

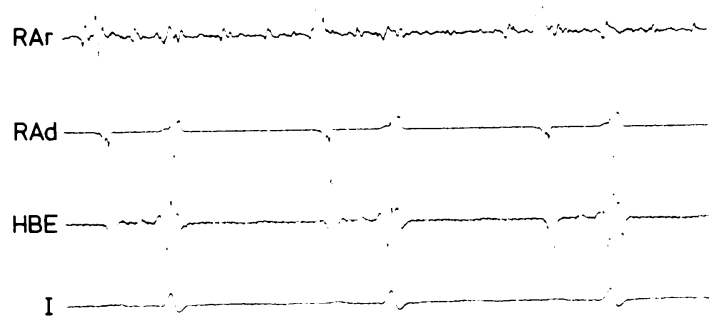

aVF

$$
\mathrm{V} 1
$$$$
\text { V6 }
$$

$100 \mathrm{~mm} / \mathrm{s}$
Fig. 3 Electrocardiogram illustrating the recipient atrium in atrial fibrillation while the donor atrium remains in sinus rhythm. $R A r$, recipient atrial electrogram; $R A d$, donor atrial electrogram; $H B E$, His bundle electrogram. I, aVF, VI, and V6 are surface electrocardiographic leads.

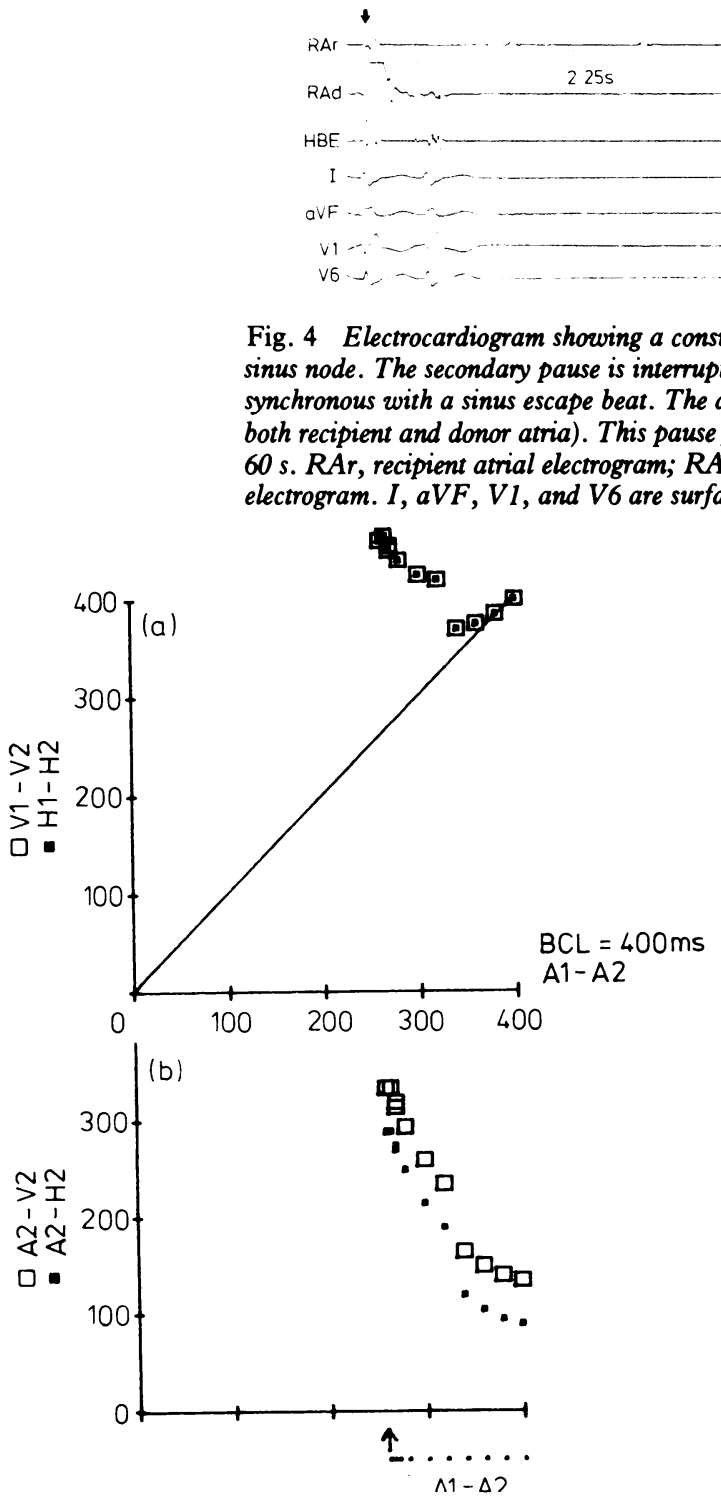

Fig. 5 Anterograde conduction curve showing functional duality of atrioventricular nodal conduction. The curve to the right of the discontinuity represents fast pathway conduction and to the left of the discontinuity slow pathway conduction. In this example there is a jump in the A2-H2 interval of $70 \mathrm{~ms}$ for a 20 $m s$ decrease in the Al-A2 coupling interval. BCL, basic cycle length. 
(a)

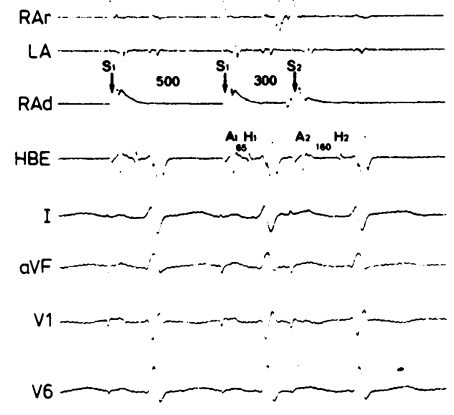

(b)

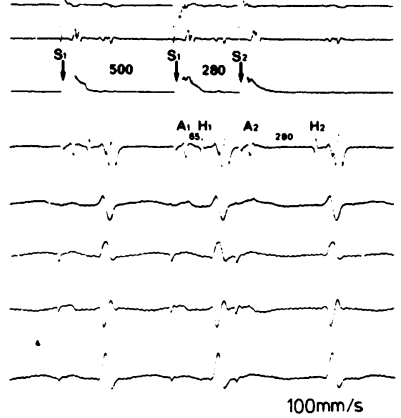

Fig. 6 Electrocardiogram showing the jump in $A H$ interval as the fast pathway becomes refractory. Panel a shows a basic driven pacing cycle length (S1-S1) of 500 ms with an $A H$ interval (A1-H1) of 65 ms followed by an atrial extrastimulus with a coupling interval (S1-S2) of 300 ms. The extrastimulus (S2) conducts through the fast pathway with an AH interval (A2-H2) of $160 \mathrm{~ms}$. In panel b with an S1-S2 interval of $280 \mathrm{~ms}$ the refractory period of the fast pathway has been exceeded and the extrastimulus (S2) conducts through the slow pathway with an $A H$ interval (A2-H2) of $280 \mathrm{~ms}$. All measurements are in ms. $R A r$, recipient right atrial electrogram; $L A$, left atrial electrogram; $R A d$, donor right atrial electrogram; HBE, His bundle electrogram. I, aVF, V1, and V6 are surface electrocardiographic leads.

The sinus cycle length was greater than $1000 \mathrm{~ms}$ in one of the donor atria and in four of the recipient atria. Sinus node recovery times and corrected recovery times were prolonged in four (of the 14) donor atria and in six (of the 10) recipient atria. In two patients (cases 8 and 9) the donor sinus node recovery time exceeded $2500 \mathrm{~ms}$ (Fig. 4). One of these patients (case 9) had an implanted ventricular pacemaker, the other did not. The uncorrected sinoatrial conduction time (measured using the method of Strauss ${ }^{24}$ ) of the donor atria was prolonged in four patients $(206 \mathrm{~ms}$, $220 \mathrm{~ms}, 240 \mathrm{~ms}$, and $460 \mathrm{~ms}$ ) and abnormally short in one patient $(5 \mathrm{~ms})$. Four of these five patients had prolonged donor sinus node recovery times. In one patient the dramatically prolonged sinoatrial conduction time $(460 \mathrm{~ms})$ was due to considerable sinus node suppression during the zone of reset. Even after correcting this value for sinus node suppression, however, the sinoatrial conduction time was still prolonged at $275 \mathrm{~ms}$. The recipient sinoatrial conduction time was prolonged in four patients (222 $\mathrm{ms}, 234 \mathrm{~ms}, 235 \mathrm{~ms}$, and $282 \mathrm{~ms}$ ), but only two of these patients had prolonged recovery times.

\section{REFRACTORINESS}

The atrial, ventricular, and atrioventricular refractory periods estimated at a cycle length of $500 \mathrm{~ms}$ were all within normal limits. Four patients had evidence of functional duality of anterograde atrioventricular nodal conduction during assessment of atrioventricu- lar nodal refractoriness at a pacing cycle length of either $500 \mathrm{~ms}$ (three patients) or $400 \mathrm{~ms}$ (three patients) (Figs. 5 and 6). Jumps in the A2-H2 interval ranged from an increase of $50 \mathrm{~ms}$ for a $10 \mathrm{~ms}$ decrease in the A1-A2 coupling interval to an increase of $105 \mathrm{~ms}$ for a $5 \mathrm{~ms}$ decrease in A1-A2 interval. Only one patient showed functional duality of conduction in the retrograde direction.

From these previous results and the table it can be seen that only four patients (cases $4,5,11$, and 12) had entirely normal electrophysiology of the transplanted donor heart.

\section{AMBULATORY ELECTROCARDIOGRAPHIC RECORDINGS}

A total of $\mathbf{4 4 7}$ hours of ambulatory electrocardiographic recordings were performed in the 14 patients. The period of monitoring ranged from 20 to 70 (mean 31.9) hours. Seven patients had no abnormalities. One patient had flutter of the donor atrium on his first 24 hour recording. He had no clinical, biochemical, or haematological evidence of rejection and underwent DC cardioversion under a general anaesthetic five hours before his electrophysiological study, during which donor sinus node function was normal. There was no abnormality on his second recording. Three patients (cases 1, 3, and 11) had infrequent unimorphological ventricular premature beats (less than one per hour), but in one of these patients (case 1) the premature beats occurred in couplets. Two of these 
three patients (case 1 and 3) also had a moderate number of atrial premature beats, which in case 1 occurred in couplets and on one occasion initiated a 3 $s$ run of atrial fibrillation. No episode of ventricular tachyarrhythmia was recorded in any patient.

Three patients (cases 8,9 , and 14) showed relative bradycardias throughout their recordings. Two of these patients (cases 9 and 14) had implanted ventricular pacemakers, the other did not (case 8). All three patients had abnormal donor sinus node function tests during their electrophysiological evaluation. Patient case 8 (corrected sinus node recovery time $1440 \mathrm{~ms}$ ) showed sudden changes in sinus rate, sometimes by as much as 33 beats/min, with the initial pause interrupted by a junctional escape beat on occasions. The sinus rate fell to 57 beats/min at times, even during waking hours. The recordings in case 9 showed sinus rates less than 80 beats/min at all times and ventricular demand pacing at 70 beats/min for a high proportion of the 24 hours including waking hours. This patient had a corrected donor sinus node recovery time of $1360 \mathrm{~ms}$ during her electrophysiological study. The recording in case 14, who had a corrected donor sinus node recovery time of $935 \mathrm{~ms}$, showed several episodes of ventricular demand pacing at 70 beats/min and donor sinus rates never exceeding 85 beats $/ \mathrm{min}$. This patient also had sudden changes in heart rate, which usually followed an atrial premature beat. The $P$ wave of the slower atrial rhythm had a different morphology and vector to that of the faster rate, suggesting different sites of origin of the two atrial pacemakers.

\section{Discussion}

The incidence and significance of abnormalities of the atrioventricular conduction system found during invasive electrophysiological studies of symptomatic patients and patients with obvious conduction system disease, or during routine surface electrocardiographic screening of asymptomatic subjects, have been well reported. $349101834-37$ The incidence and significance of abnormalities of the conduction system detected during electrophysiological evaluations in asymptomatic patients with normal surface electrocardiograms are, naturally, unknown. Similarly, the influence of the denervated state of the transplanted heart on the significance of abnormalities detected is unclear. Other studies from our laboratory (unpublished observations) have shown that the electrophysiological characteristics of the atrioventricular conduction system of the transplanted heart are similar to those of the innervated heart and therefore the significance of conduction abnormalities found in the transplanted heart may probably be equated to that reported for the innervated heart.
Four patients had a prolonged intra-atrial conduction time. Impulse conduction from the sinus node to the atrioventricular junction probably takes place primarily through muscular connections. ${ }^{38}$ The surgical technique entailed in cardiac transplantation may result in damage to these muscular connections, and this, together with the physical distortion of the donor atrium, may account for the high incidence of intra-atrial conduction delay in these patients. Such conduction delay may result in first degree heart block, ${ }^{18}$ but spontaneous higher degrees of block have never been reported. Second degree Wenckebach type block within the atrium has, however, been reported with atrial pacing. ${ }^{39} 40$

The finding of a slightly prolonged $\mathrm{HV}$ interval in two patients, who were asymptomatic and had normal surface electrocardiograms, is probably of no clinical significance. Although the significance of a prolonged $\mathrm{HV}$ interval in patients presenting with syncope is well documented, ${ }^{36}$ in asymptomatic patients, even those with bundle branch block, reports of the prognostic implications of His-Purkinje conduction delay have been conflicting. ${ }^{34}$

Two of the 14 patients had complete right bundle branch block, although in one of these this had been present before operation in the donor heart. This compares with reported prevalences of $0.18 \%$ in 122043 airmen, ${ }^{35} 0.4 \%$ in an insurance population of 30000 subjects, ${ }^{41} 0.75 \%$ in 3983 airmen, ${ }^{34}$ and $1 \cdot 15 \%$ in 8770 members of an average population. ${ }^{42}$ The long term follow up studies of Mathewson and Varnam, ${ }^{34}$ Reusch and Vivas, ${ }^{42}$ and Rotman and Triebwasser ${ }^{37}$ of subjects with right bundle branch block showed that in subjects with no evidence of heart disease and a normal axis the only deaths were due to non-cardiac causes and no cases of advanced atrioventricular block were recorded. Similarly, in the mortality study of Rodstein et al. ${ }^{41}$ the presence of right bundle branch block did not imply a higher mortality in the absence of other major cardiac abnormalities.

The limitations of invasive electrophysiological testing of sinus node function in normally innervated $\operatorname{man}^{6725}$ are well known. There is often a poor correlation between the results of electrophysiological testing and the presence or absence of symptoms. ${ }^{643}$ and clinical signs and symptoms may result primarily from escape pacemaker malfunction and not from the sinus node malfunction itself. ${ }^{44}$ The effect of the autonomic nervous system may be important, ${ }^{45}$ and perhaps of prime importance, in terms of the prognosis of sinus node disease, is the coexistence of underlying heart disease. ${ }^{24} 46$

In the absence of autonomic neural influences formal testing of donor sinus node function in transplant patients may provide a more reliable indicator of true intrinsic sinus node function than in the innervated 
heart, as has been suggested from studies using pharmacological autonomic blockade. ${ }^{4748}$ The spontaneous abnormalities of sinus node function found during ambulatory electrocardiographic monitoring in three of the four patients with abnormal sinus node function tests during invasive testing but in none of the patients with normal sinus node function tests add further credence to this theory. These three patients also showed relative bradycardias during their 24 hour recordings. In the absence of the normally dominant vagal tone $e^{49}$ the resting heart rate of the denervated sinus node tends to be faster than in the innervated heart with resting heart rates of 100 beats/min or greater.

The clinical course of the sick sinus syndrome may be variable but tends to be progressive, ${ }^{1}$ and its prognosis is uncertain. The ultimate prognosis depends partly on the characteristics and stability of the escape rhythm of lower pacemakers, which may be unreliable in transplant patients. ${ }^{14}$ The finding of abnormalities of donor sinus node function during invasive testing in transplant patients may therefore be of greater clinical significance than abnormalities found in patients with normally innervated hearts. The high incidence of recipient sinus node disease may well be related to underlying disease before the operation and to the relative ischaemia induced by the surgery but is probably of limited clinical importance.

Four of the 13 patients in whom atrioventricular nodal refractory periods were assessed showed functional duality of atrioventricular nodal conduction. Dual atrioventricular pathways predispose to atrioventricular nodal re-entrant tachycardia in $\operatorname{man}^{303150}$ as originally hypothesised by Moe et al. ${ }^{51}$ and later shown by Mendez and Moe ${ }^{52}$ in animal experiments, and they are a common finding during electrophysiological testing of patients with supraventricular tachycardia. ${ }^{53}$ They are also a relatively common finding in arrhythmia free adults ${ }^{54}$ and children. ${ }^{3255}$ Denes et al. ${ }^{54}$ showed dual pathways in 41 out of 397 patients studied. Sixteen of these 41 patients were arrhythmia free. Similarly Thapar and Gillette $^{32}$ reported an incidence of $29 \%$, and Casta $e t$ al. ${ }^{55}$ reported an incidence of $35 \%$ in arrhythmia free children with a variety of congenital cardiac defects. This high incidence of dual atrioventricular nodal pathways in children may be related to their considerably shorter atrial refractory periods, ${ }^{55}$ which would allow the unmasking and increased expression of dual pathways. The relatively high incidence of dual pathways in transplant patients $(31 \%)$ may be related to the young age of the donor hearts, to the slightly shorter refractory periods of the atrioventricular conduction system compared with innervated hearts, and, to an unknown extent, to the denervated state of the transplanted heart. All four patients had retrograde ventriculoatrial conduction, but only one patient had retrograde functional duality of conduction and no patient showed atrial echoes during programmed extrastimulation at either basic pacing cycle length. Hence no patient developed sustained re-entrant tachycardia. Although dual pathways are the electrophysiological substrate for atrioventricular reentrant tachycardia, its initiation depends on an interplay of many factors. It is not known whether the finding of dual pathways in an arrhythmia free patient is a benign electrophysiological phenomenon representing the normal functional characteristics of the human atrioventricular node or whether these patients are at risk of developing a clinically important arrhythmia. Long term longitudinal studies of such patients are not available.

Although previous studies from Stanford University 1112 have reported a high incidence of both atrial and ventricular arrhythmias in asymptomatic transplant patients, this was not borne out by us. Infrequent atrial and ventricular premature beats were recorded in only four patients, and the only appreciable arrhythmia recorded was a short run of atrial fibrillation in one of these patients. The period of recording was obviously relatively short and few conclusions can be drawn about the incidence and significance of arrhythmias in these patients.

Asymptomatic, relatively long term survivors of cardiac transplantation thus have a high incidence of electrophysiological abnormalities. As already indicated, abnormalities of donor sinus node function may well be of clinical significance, although long term follow up studies are required to clarify this point. Limited data from studies in normally innervated man suggest that the abnormalities found within the atrioventricular conduction system are probably relatively benign but obviously it is impossible, and unwise, to make direct comparisons with the innervated heart because of the unique denervated state of the transplanted heart.

\section{References}

1 Ferrer MI. The sick sinus syndrome. Circulation 1973; 47: 635-41.

2 Levites R, Haft JI. Significance of first degree heart block (prolonged $\mathrm{P}-\mathrm{R}$ interval) in bifascicular block. Am f Cardiol 1974; 34: 259-64.

3 Dhingra RC, Denes P, Wu D, et al. Prospective observations in patients with chronic bundle branch block and marked H-V prolongation. Circulation 1976; 53: 600-4.

4 Scheinman MM, Peters RW, Modin G, Brennan M, Mies C, O'Young J. Prognostic value of infranodal conduction time in patients with chronic bundle branch block. Circulation 1977; 56: 240-4. 
5 Narula OS, Narula JT. Junctional pacemakers in man. Response to overdrive suppression with and without parasympathetic blockade. Circulation 1978; 57: 880-9.

6 Gupta PK, Lichstein E, Chadda KD, Badui E. Appraisal of sinus nodal recovery time in patients with sick sinus syndrome. Am f Cardiol 1974; 34: 265-70.

7 Crook B, Kitson D, McComish M, Jewitt D. Indirect measurement of sinoatrial conduction time in patients with sinoatrial disease and in controls. Br Heart $\mathcal{F}$ 1977; 39: 771-7.

8 Narula OS, Samet P. Wenckebach and Mobitz type II A-V block due to block within the His bundle and bundle branches. Circulation 1970; 41: 947-65.

9 Dhingra RC, Denes P, Wu D, Chuquimia R, Rosen KM. The significance of second degree atrioventricular block and bundle branch block. Observations regarding site and type of block. Circulation 1974; 49: 638-46.

10 Strasberg B, Amat-y-Leon F, Dhingra RC, et al. Natural history of chronic second-degree atrioventricular nodal block. Circulation 1981; 63: 1043-9.

11 Berke DK, Graham AF, Schroeder JS, Harrison DC. Arrhythmias in the denervated transplanted human heart. Circulation 1973; $47 / 48$ (suppl III): III-112-5.

12 Schroeder JS, Berke DK, Graham AF, Rider AK, Harrison DC. Arrhythmias after cardiac transplantation. Am $\mathcal{F}$ Cardiol 1974; 33: 604-7.

13 Mason JW, Harrison DC. Electrophysiology and electropharmacology of the transplanted human heart. In: Narula OS, ed. Cardiac arrhythmias: electrophysiology, diagnosis and management. Baltimore: Williams and Wilkins, 1979: 66-81.

14 Mackintosh AF, Carmichael DJ, Wren C, Cory-Pearce $R$, English TAH. Sinus node function in first three weeks after cardiac transplantation. Br Heart $\mathcal{F} 1982$; 48: 584-8.

15 Stinson EB, Dong E Jr, Iben AB, Shumway NE. Cardiac transplantation in man. III. Surgical aspects. Am $\mathcal{F}$ Surg 1969; 118: 182-7.

16 Hellestrand KJ, Bexton RS, Nathan AW, Spurrell RAJ, Camm AJ. Acute electrophysiological effects of flecainide acetate on cardiac conduction and refractoriness in man. Br Heart $\mathcal{F}$ 1982; 48: 140-8.

17 Castellanos A Jr, Castillo CA, Agha AS. Contribution of His bundle recordings to the understanding of clinical arrhythmias. Am 7 Cardiol 1971: 28: 499-508.

18 Narula OS, Scherlag BJ, Samet P, Javier RP. Atrioventricular block. Localization and classification by $\mathrm{His}$ bundle recordings. Am $\mathcal{F}$ Med 1971; 50: 146-65.

19 Castellanos A, Myerburg RJ. The resting electrocardiogram. In: Hurst JW, ed. The heart. 2nd ed. New York: McGraw-Hill, 1982: 257-72.

20 Lipman BS, Massie E, Kleiger RE. Clinical scalar electrocardiography. 6th ed. Chicago: Year Book Medical Publishers, 1972: 670.

21 Mandel W, Hayakawa H, Danzig R, Marcus HS. Evaluation of sino-atrial node function in man by overdrive suppression. Circulation 1971; 44: 59-66.

22 Narula OS, Samet P, Javier RP. Significance of the sinus-node recovery time. Circulation 1972; 45: 140-58.

23 Rosen KM, Loeb HS, Sinno MZ, Rahimtoola SH, Gunnar RM. Cardiac conduction in patients with symptomatic sinus node disease. Circulation 1971; 43: 836-44.
24 Strauss HC, Bigger JT Jr, Saroff AL, Giardina EGV. Electrophysiologic evaluation of sinus node function in patients with sinus node dysfunction. Circulation 1976; 53: 763-76.

25 Strauss HC, Scheinman MM, LaBarre A, Browning DJ, Benditt DG, Wallace AG. Programmed atrial stimulation and rapid atrial pacing in patients with sinus pauses and sinoatrial exit block. In: Bonke FIM, ed. The sinus node. Structure, function and clinical relevance. The Hague: Martinus Nijhoff, 1978: 56-64.

26 Wit AL, Weiss MB, Berkowitz WD, Rosen KM, Steiner C, Damato AN. Patterns of atrioventricular conduction in the human heart. Circ Res 1970; 27: 345-59.

27 Akhtar M, Damato AN, Batsford WP, Ruskin JN, Ogunkelu JB. A comparative analysis of antegrade and retrograde conduction patterns in man. Circulation 1975; 52: 766-78.

28 Denes P, Wu D, Dhingra R, Pietras RJ, Rosen KM. The effects of cycle length on cardiac refractory periods in man. Circulation 1974; 49: 32-41.

29 Schuilenburg RM, Durrer D. Conduction disturbances located within the His bundle. Circulation 1972; 45: 612-28.

30 Denes P, Wu D, Dhingra RC, Chuquimia R, Rosen KM. Demonstration of dual A-V nodal pathways in patients with paroxysmal supraventricular tachycardia. Circulation 1973; 48: 549-55.

31 Rosen KM, Mehta A, Miller RA. Demonstration of dual atrioventricular nodal pathways in man. Am $\mathcal{f}$ Cardiol 1974; 33: 291-4.

32 Thapar MK, Gillette PC. Dual atrioventricular nodal pathways: a common electrophysiologic response in children. Circulation 1979; 60: 1369-74.

33 Bexton RS, Hellestrand KJ, Cory-Pearce R, Spurrell RAJ, English TAH, Camm AJ. Unusual atrial potentials in a cardiac transplant recipient. Possible synchronization between donor and recipient atria. $\mathcal{F}$ Electrocardiol 1983; 16: 313-22.

34 Mathewson FAL, Varnam GS. Abnormal electrocardiograms in apparently healthy people. I. Long term follow-up study. Circulation 1960; 21: 196-203.

35 Hiss RG, Lamb LE. Electrocardiographic findings in 122,043 individuals. Circulation 1962; 25: 947-61.

36 Touboul P, Ibrahim M. Atrioventricular conduction defects in patients presenting with syncope and normal PR interval. Br Heart $\mathcal{F}$ 1972; 34: 1005-11.

37 Rotman M, Triebwasser JH. A clinical and follow-up study of right and left bundle branch block. Circulation 1975; 51: 477-84.

38 Merideth J, Titus JL. The anatomic atrial connections between sinus and A-V node. Circulation 1968; 37: 56679.

39 Narula OS, Runge M, Samet P. Second-degree Wenckebach type AV block due to block within the atrium. $\mathrm{Br}$ Heart f 1972; 34: 1127-36.

40 Castellanos A, Iyengar R, Agha AS, Castillo CA. Wenckebach phenomenon within the atria. Br Heart $\mathcal{F}$ 1972; 34: 1121-6.

41 Rodstein M, Gubner R, Mills JP, Lovell JF, Ungerleider HE. A mortality study in bundle branch block. Arch Intern Med 1951; 87: 663-8.

42 Reusch CS, Vivas JR. Clinical analysis of right bundle 
branch block. Am Heart $\mathcal{f}$ 1959; 58: 543-6.

43 Breithardt G, Seipel L, Loogen F. Sinus node recovery time and calculated sinoatrial conduction time in normal subjects and patients with sinus node dysfunction. Circulation 1977; 56: 43-50.

44 Mandel WJ, Obayashi K, Laks MM. Overview of the sick sinus syndrome. Chest 1974; 66: 223-4.

45 Jordan JL, Yamaguchi I, Mandel WJ. Studies on the mechanism of sinus node dysfunction in the sick sinus syndrome. Circulation 1978; 57: 217-23.

46 Scheinman MM, Strauss HC, Abbott JA. Electrophysiologic testing for patients with sinus node dysfunction. F Electrocardiol 1979; 12: 211-6.

47 Desai JM, Scheinman MM, Strauss HC, Massie B, O'Young J. Electrophysiologic effects of combined autonomic blockade in patients with sinus node disease. Circulation 1981; 63: 953-60.

48 Szatmary L, Medvedowsky JL, Barnay C, Coste A, Pisapia A. Electrophysiological effect of overdrive suppression and combined autonomic blockade with propranolol and atropine in patients with sinus node dysfunction. Eur Heart f 1982; 3: 47-55.

49 Jose $\mathrm{AD}$, Collison $\mathrm{D}$. The normal range and determinants of the intrinsic heart rate in man. Cardiovasc Res 1970; 4: 160-7.
50 Wu D, Denes P, Dhingra R, Pietras RJ, Rosen KM. New manifestations of dual A-V nodal pathways. Eur $\mathcal{F}$ Cardiol 1975; 2: 459-66.

51 Moe GK, Preston JB, Burlington H. Physiologic evidence for a dual A-V transmission system. Circ Res 1956; 4: 357-75.

52 Mendez C, Moe GK. Demonstration of a dual A-V nodal conduction system in the isolated rabbit heart. Circ Res 1966; 19: 378-93.

53 Wu D, Denes P, Amat-y-Leon F, et al. Clinical, electrocardiographic and electrophysiologic observations in patients with paroxysmal supraventricular tachycardia. Am $\mathcal{F}$ Cardiol 1978; 41: 1045-51.

54 Denes P, Wu D, Dhingra R, Amat-y-Leon F, Wyndham C, Rosen KM. Dual atrioventricular nodal pathways. A common electrophysiological response. Br Heart $\mathcal{F}$ 1975; 37: 1069-76.

55 Casta A, Wolff GS, Mehta AV, et al. Dual atrioventricular nodal pathways: a benign finding in arrhythmia-free children with heart disease. Am $\mathcal{F}$ Cardiol 1980; 46: 1013-8.

Requests for reprints to Dr R S Bexton, Department of Cardiology, Freeman Hospital, Freeman Road, Newcastle upon Tyne NE7 7DN. 